\section{Beyond IgA: the mucosal immunoglobulin alphabet}

Secretory immunoglobulins are an important component of the detection and neutralization arm of effectors that operate at all mucosal sites. Ample data have been published on the roles played by $\lg \mathrm{A}$ and $\operatorname{lgM}$ as well as by their transporter, the polymeric Ig receptor (plgR). ${ }^{1}$ However, the contribution of the remainder of the mucosal immunoglobulin alphabet is often overlooked in spite of a now considerable body of evidence documenting their role in the maintenance of organismal homeostasis. It has often been argued that the presence of these immunoglobulins in mucosal secretions results from passive diffusion across the epithelial layer, but this is unlikely given that the tight junctions between epithelial cells in these locations exclude the passage of molecules larger than $0.5 \mathrm{kDa}$ (ref. 2). The identification of transport-competent receptors for several other classes of immunoglobulins has allowed considerable inroads to be made into the study of the function of such molecules at mucosal locations.

Perhaps the first of the immunoglobulins to be studied in detail was IgG, the concentration of which in mucosal secretions often exceeds that of the corresponding quantity of $\operatorname{lgM} .^{3,4}$ In addition, the concept of passive diffusion is largely incongruous with the documented rate of $\lg G$ secretion into colonic fluid, measured at $34 \mathrm{mg} / \mathrm{min}$, considering that normal serum values for this immunoglobulin range from 5 to $19 \mathrm{mg} / \mathrm{ml}$ (ref. 3). Identification of an IgG-specific receptor, the neonatal $F c$ receptor $(F c R n)$, confirmed that $\lg G$ is actively transported across the mucosal epithelium in a pH-dependent manner in many species, including humans and nonhuman primates. ${ }^{5} \mathrm{FcRn}$ expression in placental syncytiotrophoblasts and intestinal epithelial cells is known to be critical for the transport of maternal lgG to both pre- and postnatal infants. ${ }^{6}$ Adding another level of complexity, FcRn-mediated IgG transcytosis is bidirectional such that IgG not only can be delivered into the intestinal lumen but can also be retrieved, along with any bound cargo, from the lumen and deposited into the intestinal lamina propria. This mechanism of lumenal immune complex retrieval is capable of priming antigen-specific responses that result in the clearance of enteric bacterial infections in mouse models expressing only human $\mathrm{FcRn}$ in the intestinal epithelium. ${ }^{7,8}$ Expression of $\mathrm{FcRn}$ in various locations within the respiratory mucosa has also been established and is currently being investigated as a possible mode of drug delivery in humans. 9,10

Confirmation that soluble $\lg \mathrm{E}$ is an important player at mucosal sites is also accumulating. Local isotype switching to $\lg \mathrm{E}$ in the airway mucosa has recently been demonstrated, and the presence of $\lg E$ in nasal lavage fluid has been documented. ${ }^{11,12}$ Additionally, during helminth infections, up to $99 \%$ of the locally produced IgE enters the intestinal lumen, a highly unlikely scenario in the absence of active shuttling. ${ }^{13}$ Discovery that the $\lg \mathrm{E}$-specific receptor CD23/FceRII, which is expressed on enterocytes, can mediate transepithelial transport of its cargo elucidated the mechanism explaining these phenomena. ${ }^{14}$ As is the case for IgG transport by FcRn, CD23-mediated transport of IgE is bidirectional and able to retrieve immune complexes from the lumen. ${ }^{15}$ The rate of basolateral $\rightarrow$ apical transport was found to exceed that of apical $\rightarrow$ basolateral transit for immune complexes, but the opposite was true for monomeric $\operatorname{lgE}$. Such a pattern is consistent with the movement of monomeric $\lg \mathrm{E}$ into the intestinal lumen, aggregation with lumenal antigens, and subsequent retrieval of a portion of these complexes for delivery to interstitial antigen-presenting cells capable of immune-response modulation. That the antigens survive this transport in an intact form has been clearly demonstrated, as has the fact that this mechanism contributes to increased uptake of food allergens in sensitized individuals. ${ }^{16}$ Furthermore, transcytosed $\lg \mathrm{E}$ aggregates may bind to high-affinity $\lg \mathrm{E}$ receptors on mucosal mast cells, thereby triggering their degranulation and affecting barrier and transport properties of the intestinal epithelium. ${ }^{17}$ Similar lgE-mediated effects are likely to be manifest in the respiratory mucosa, given that specific IgEs have been linked to the development of asthma and rhinitis. ${ }^{18,19}$

In contrast to the case with $\lg G$ and $\lg E$, a specific transporter capable of mediating transepithelial IgD transport has not been identified. However, the presence of large numbers of lgD-secreting plasma cells in the upper respiratory tract, particularly the nasal mucosa and tonsils, as well as in mammary glands has led to the suggestion that selective $\lg \mathrm{D}$ transport is a physiologically relevant process. ${ }^{20}$ This argument is bolstered by the finding that $\operatorname{lgD}$ levels within breast milk exceed those found in serum. ${ }^{21}$ Known $\operatorname{lgD}$ specificities against a range of viral and bacterial antigens would imply that, if a bidirectionally competent receptor exists, retrieval of lgD/antigen immune complexes from the airway lumen might contribute to the orchestration of immune responses at these mucosal sites. ${ }^{21}$ The growing appreciation of the importance of all immunoglobulin classes at mucosal sites will probably serve as an impetus to identify and characterize the relevant $\lg D$ receptor.

Although the importance of secretory lgA and IgM cannot be denied, it can no longer be overlooked that other immunoglobulins have an important role in the spelling out of relevant mucosal defense strategies.

\section{ACKNOWLEDGMENTS}

This work was supported by the Canadian Institutes of Health Research (K.B.), National Institutes of Health grants DK53056 (R.S.B.) and DK084424 (W.I.L.), and Harvard Digestive Disease Center grant P30 DK034854.

\section{DISCLOSURE}

W.I.L. and R.S.B. have patents on FcRn that are licensed to Syntonix-Biogen Idec.

\author{
Kristi Baker \\ Wayne I Lencer \\ Richard S Blumberg, Associate Editor
}




\section{NEWS \& HIGHLIGHTS}

(C) 2010 Society for Mucosal Immunology

1. Brandtzaeg, P. Mucosal immunity: induction, dissemination, and effector functions. Scand. J. Immunol. 70, 505-515 (2009).

2. Van Itallie, C.M. \& Anderson, J.M. The molecular physiology of tight junction pores. Physiology 19, 331-338 (2004).

3. Ogra, P.L., Mestecky, J., Lamm, M.E, Strober, W., Bienenstock, J. \& McGhee, J.R., eds. Mucosal Immunology 2nd edn (Academic Press, San Diego, CA, 1999).

4. Yoshida, M. et al. IgG transport across mucosal barriers by neonatal Fc receptor for IgG and mucosal immunity. Springer Semin. Immunopathol. 28, 397-403 (2006).

5. Simister, N.E. \& Rees, A.R. Isolation and characterization of an Fc receptor from neonatal rat small intestine. Eur. J. Immunol. 15, 733-738 (1985).

6. Baker, K. et al. Immune and non-immune functions of the (not so) neonatal Fc receptor, FcRn. Semin. Immunopathol. 31, 223-236 (2009).

7. Yoshida, M. et al. Human neonatal Fc receptor mediates transport of IgG into luminal secretions for delivery of antigens to mucosal dendritic cells. Immunity 20, 769-783 (2004).
8. Qiao, S.W. et al. Dependence of antibodymediated presentation of antigen on FcRn. Proc. Natl. Acad. Sci. USA 105, 9337-9342 (2008).

9. Spiekermann, G.M. et al. Receptor-mediated immunoglobulin G transport across mucosal barriers in adult life: functional expression of FCRn in the mammalian lung. J. Exp. Med. 196, 303-310 (2002).

10. Bitonti, A.J. \& Dumont, J.A. Pulmonary administration of therapeutic proteins using an immunoglobulin transport pathway. Adv. Drug Deliv. Rev. 58, 1106-1118 (2006).

11. Fiset, P.O., Cameron, L. \& Hamid, Q. Local isotype switching to $\lg \mathrm{E}$ in airway mucosa. J. Allergy Clin. Immunol. 116, 233-236 (2005).

12. Wise, S.K., Ahn, C.N. \& Schlosser, R.J. Localized immunoglobulin E expression in allergic rhinitis and nasal polyposis. Curr. Opin. Otolaryngol. Head Neck Surg. 17, 216-222 (2009).

13. Bell, R.G. IgE, allergies and helminth parasites: a new perspective on an old conundrum. Immunol. Cell Biol. 74, 337-345 (1996).

14. Yang, P.-C., Berin, M.C., Yu, L.C.H., Conrad, D.H. \& Perdue, M.H. Enhanced intestinal transepithelial antigen transport in allergic rats is mediated by lgE and CD23 (FcepsilonRII). J. Clin. Invest. 106, 879-886 (2000).

15. Tu, Y. \& Perdue, M.H. CD23-mediated transport of IgE/immune complexes across human intestinal epithelium: role of p38 MAPK. Am. J. Physiol. Gastrointest. Liver Physiol. 291, G532-G538 (2006).

16. Bevilacqua, C. et al. Food allergens are protected from degradation during CD23-mediated transepithelial transport. Int. Arch. Allergy Immunol. 135, 108-116 (2004).

17. Yu, L.C.H. \& Perdue, M.H. Role of mast cells in intestinal mucosal function: studies in models of hypersensitivity and stress. Immunol. Rev. 179 , 61-73 (2001).

18. Suh, Y.J. et al. Specific immunoglobulin E for staphylococcal enterotoxins in nasal polyps from patients with aspirin-intolerant asthma. Clin. Exp. Allergy 34, 1270-1275 (2004).

19. Rondón, C. et al. Local lgE production and positive nasal provocation test in patients with persistent nonallergic rhinitis. J. Allergy Clin. Immunol. 119, 899-905 (2007).

20. Litwin, D., Zehr, B.D. \& Insel, R.A. Selective concentration of IgD class-specific antibodies in human milk. Clin. \& Exp. Immunol. 80, 263-267 (1990).

21. Preud'homme, J.-L., Petit, I., Barra, A., Morel, J.-C.L.F. \& Lelièvre E. Structural and functional properties of membrane and secreted lgD. Mol. Immunol. 37, 871-887 (2000). 